\title{
Atmosphere-Cryosphere Coupled Model for Regional Climate Applications
}

\author{
Ki-Hong Min ${ }^{1,2}$ and Wen-Yih Sun ${ }^{2}$ \\ ${ }^{1}$ Department of Astronomy and Atmospheric Sciences, Kyungpook National University, \\ 80 Daehak-ro, Buk-gu, Daegu 702-701, Republic of Korea \\ ${ }^{2}$ Department of Earth, Atmospheric and Planetary Sciences, Purdue University, West Lafayette, IN 47907, USA
}

Correspondence should be addressed to Ki-Hong Min; kmin@knu.ac.kr

Received 25 April 2014; Revised 13 November 2014; Accepted 15 November 2014

Academic Editor: Lian Xie

Copyright (C) 2015 K.-H. Min and W.-Y. Sun. This is an open access article distributed under the Creative Commons Attribution License, which permits unrestricted use, distribution, and reproduction in any medium, provided the original work is properly cited.

There have been significant advances in our understanding of the climate system, but two major problems still exist in modeling atmospheric response during cold seasons: (a) lack of detailed physical description of snow and frozen soil in the land-surface schemes and (b) insufficient understanding of regional climate response from the cryosphere. A multilayer snow land-surface model based on the conservations of heat and water substance inside the soil and snow is coupled to an atmospheric RCM, to investigate the effect of snow, snowmelt, and soil frost on the atmosphere during cold seasons. The coupled RCM shows much improvement in moisture and temperature simulation for March-April of 1997 compared to simple parameterizations used in GCMs. The importance of such processes in RCM simulation is more pronounced in mid-to-high latitudes during the transition period (winter-spring) affected by changes in surface energy and the hydrological cycle. The effect of including cryosphere physics through snow-albedo feedback mechanism changes the meridional temperature gradients and in turn changes the location of weather systems passing over the region. The implications from our study suggest that, to reduce the uncertainties and better assess the impacts of climate change, RCM simulations should include the detailed snow and frozen soil processes.

\section{Introduction}

Accurate simulation of snowmelt runoff and infiltration is crucial for the mesoscale numerical simulation of atmosphere-land interactions $[1,2]$. Including detailed snow and frozen soil physics can improve not only seasonal cycle of snowmelt in climate simulations, but also the surface energy and water budgets in high and temperate latitudes [3, 4]. Studies suggest that soil moisture, temperature, and snow exhibit persistence on seasonal to interannual time scales $[5,6]$. Together with external forcing and internal landsurface dynamics, this seasonal persistence has important implications for the extended prediction of climatic and hydrologic extremes. Accurate prediction of snow, snowmelt, and frozen soil processes are important to the accuracy of regional climate simulation during cold season. Although considerable model variability exists for snow simulations, the onset and duration of snowmelt are of critical importance to both predicted atmospheric fluxes and the hydrological cycle [7]. Thus, accurate regional climate model (RCM) simulations with reduced uncertainties are needed to better assess the limits of climate change impacts.

For several decades, atmospheric general circulation models (GCMs) have been widely used to answer questions relating to the Earth's climate. However, typical grid separation of a few hundred kilometers and relatively simple treatment of physical parameterizations in GCMs are well known deficiencies and limitations in the detailed reproduction of regional climate.

The dynamic downscaling method takes the output fields from GCMs and uses them as initial and boundary conditions in a regional climate model (RCM) to obtain climate information on a regional scale [8-10]. The goal of regional climate modeling is to provide regional details embedded within a low-resolution global model, with the 
better representation of topography and physics. Although this strategy of one-way nesting has been commonly used for years in numerical weather prediction (NWP), this method has been increasingly applied to the downscaling of largescale driving fields in order to fill the shortcomings of global climate models $[4,11]$.

Based on reviews of many previous studies, Hong and Kanamitsu [12] summarized several issues in regional climate modeling studies. One of the problems is the "spin-up" issue that leads to climate drift. The dynamic equilibrium between the following two factors determines the climatology of a regional climate model: (1) the large-scale information provided by the lateral boundary condition (LBC) and (2) the regional characteristics produced by internal physics and dynamics of the model. In spite of many attempts to develop RCMs and to improve their capabilities and applications, regional climate solutions derived from large-scale forcing still suffer from systematic errors. These accompany synopticscale climate drift because regional climate simulations are a long-term integration over an open system with periodic update of forcing at the lateral boundaries. In spite of these problems, the systematic errors have been steadily reduced recently not only due to the better quality of large-scale driving forces, but also due to the improvement of nudging technics, internal physics, and dynamics in RCMs $[13,14]$.

Because of the uncertainties in GCMs and RCMs in reproducing climate in the Northern latitudes and over high topographic regions such as Tibetan Plateau, there has been a steady increase in RCM studies to understand the effects of snow cover. Seol and Hong [15] found that there exists a linkage between spring snow anomaly over Tibet and the East Asian summer monsoon precipitation. Their results show that RCM simulation is more robust and closer to observations than that of GCM. However, most studies utilize existing models or change/perturb the initial conditions and conduct sensitivity studies related to surface snow processes. The study presented here differs from these studies in that we utilize a newly developed snow-ice model and test its simulation results.

Several snow models or land-surface models have been developed to simulate the evolution of snow and frozen soil, including those of Anderson [16], Verseghy [17], and Stieglitz et al. [18], the Mosaic land-surface model [19], the Common Land Model (CLM) [20], the community Noah land-surface model (LSM) [21], and the Purdue snow landsurface model (SLM) [22]. A comparative study of several snow models showed the following three general model complexities to describe different snow schemes [23, 24]. (1) The first class consists of relatively simple so-called forcerestore schemes in which snow is modeled using composite snow-soil layer(s). This relatively simple class uses a single, explicit snow layer to differentiate the thermal properties and surface fluxes of the snow cover from those of the soil (e.g., Verseghy [17]). (2) The second class of schemes consists of detailed internal-snow-process schemes such as those of Anderson [16] and Jordon [25]. These models use multiple layers with a relatively fine vertical resolution and have detailed physical parameterization schemes. Their use in atmospheric models, however, has been limited by their relatively large computational expense. (3) The third class of so-called intermediate-complexity schemes is based on the internal-snow-process models (class 2). However, they use simplified versions of the physical parameterization schemes that describe the most important processes and model the minimum number of layers required to resolve the large thermal and density gradients within the snow cover (e.g., Stieglitz et al. [18]).

Regional climate over North America is not only an atmospheric response to the differential heating between the land mass and its nearby ocean but also the cause of such forcing. Specifically, most of the winter and spring precipitation in this region is primarily due to the propagation of synoptic wave systems. In spite of many previous studies on the impacts of land-surface processes in regional climate simulations [2628 ], research has mainly focused on the summer season over North America and the European continents, and relatively little work has been done from winter to spring. The lack of studies covering this season is surprising since winter snow storm and spring snowmelt contribute to major disasters and affect large-scale circulation feature of regional and global climate.

Two major problems exist in modeling the atmosphere over cold land: (a) not enough in situ data and (b) the lack of accurate physical description of snow and frozen soil in land models. Previously mentioned studies attempt to address these problems by (a) the proper utilization of remote sensing data and (b) the development of multilayer land-surface model for use with global/regional climate models that are suitable from winter to spring period and at high latitudes. The former can improve model precipitation forecasts by accurate initialization of the surface boundary conditions. The latter is important because snow strongly affects the winter-to-spring surface energy budget. Therefore, accurate initialization and representation of the snow processes in a coupled regional climate model are essential for atmospheric and hydrologic predictions. This paper studies the role of such processes to address possible deficiencies in regional climate models for studying future climate change scenarios.

\section{Purdue Regional Climate Model (PRCM) and Experiment Setup}

2.1. Description of PRCM. The PRCM is a hydrostatic primitive equation model that utilizes the terrain-following normalized pressure coordinate system $\left(\sigma_{p}\right)$ in the vertical direction. The model uses Arakawa's staggered C-grid which can calculate the divergence term more accurately. The PRCM is equipped with prognostic equations for wind, equivalent ice potential temperature, surface pressure, turbulent kinetic energy (TKE) and for all phases of water (vapor, cloud water, ice, snow, rain, and supercooled water) [26-31].

Some notable features include Goddard short- and longwave radiation parameterization [32] and Purdue-Lin 6-class microphysics scheme [29]. In the PRCM, a local reference is considered to reduce the error near steep topography for calculating the pressure gradient in a sigma coordinate system [28]. The planetary boundary layer parameterization 
TABLE 1: Comparison of PRCM land-surface scheme (LSS) with the snow land-surface model (SLM).

\begin{tabular}{|c|c|c|c|}
\hline & PRCM-LSS (current) & SLM (new) & Remarks \\
\hline $\begin{array}{l}\text { Surface } \\
\text { parameterization }\end{array}$ & $\begin{array}{l}\text { 3-layer soil and } \\
\text { one-layer vegetation } \\
\text { combined with snow }\end{array}$ & $\begin{array}{l}\text { Multilayer soil and snow, } \\
\text { one-layer vegetation }\end{array}$ & $\begin{array}{l}\text { Limited by I.C. } \\
\text { availability of soil }\end{array}$ \\
\hline Snow albedo & $\begin{array}{l}\text { Function of snow depth } \\
+ \text { background albedo }\end{array}$ & $\begin{array}{l}\text { Snow albedo depends on } \\
\text { zenith angle, snow } \\
\text { depth, and grain size }\end{array}$ & $\begin{array}{l}\text { Snow fraction of } \\
\text { vegetation and bare } \\
\text { ground }\end{array}$ \\
\hline Soil temperature & $\begin{array}{c}\text { Heat equation explicitly } \\
\text { solves for } T\end{array}$ & Enthalpy equation & $\begin{array}{l}\text { Heat transfer due to } \\
\text { water passing through } \\
\text { medium considered }\end{array}$ \\
\hline Soil moisture & No frozen soil physics & $\begin{array}{l}\text { Soil freeze/thaw } \\
\text { considered }\end{array}$ & $\begin{array}{l}\text { Liquid water and soil ice } \\
\text { can coexist }\end{array}$ \\
\hline Canopy & Single sunlit vegetation & $\begin{array}{l}\text { Both sunlit and shaded } \\
\text { fractions of vegetation }\end{array}$ & \\
\hline
\end{tabular}

is a 1.5-order closure scheme that includes TKE as a prognostic variable. Furthermore, the land-surface scheme includes Richards' equation and the diffusion equation to predict the moisture and temperature within the soil [31]. This landsurface scheme has been upgraded to take into account the effect of snow and frozen soil on vegetation, resistance to the release of soil moisture, and transpiration and evaporation from the surface of the vegetation [30]. A comprehensive summary of the current PRCM physics and numerical formulation can be found in Min [30] and Sun et al. [33].

2.2. Experiment Setup. The period chosen to study the coupled model's regional climate simulation capability and study its impact is March and April of 1997 in the Northern Plains. The north-central US experienced horrific conditions over the winter of 1996-97. Blizzard after blizzard during the second half of November through January built up an enormous snow pack; many areas had more than $3 \mathrm{~m}$ of snowfall. These amounts were as much as 2-3 times the normal annual amount. Early in March of 1997 temperatures fell below normal, delaying the onset of snowmelt. By midMarch, however, snow had melted and the snow line had moved north. Significant melt of the deep snow cover started with particularly warm conditions at the end of March and into early April. At this time, many rivers in South Dakota, southern Minnesota, and southern North Dakota were rising, in some cases well above flood stage. Conditions changed over the weekend of April 5-6, when heavy rain fell in the region already experiencing snowmelt, and then more blizzard conditions brought $30 \mathrm{~cm}$ or more of snow to the northern portions of the Red River. The most catastrophic flooding disaster of the twentieth century occurred in Minnesota and the Dakotas due to heavy spring snowmelt [34]. Floods on the Red River of the North occurred in the context of these unusual conditions and led to serious flooding throughout much of the upper Midwest. Estimated damage for the event, including all of the United States portions of the Red River, totaled approximately $\$ 4$ billion and involved 11 casualties. Of this, $\$ 3.6$ billion was lost in the immediate vicinity of Grand Forks and East Grand Forks.
The existing Purdue regional climate model's land-surface scheme (PRCM-LSS) allows for one layer of snow and uses a simple snowmelt process similar to that of a global circulation model (GCM). The effective snow-albedo calculation of PRCM-LSS can distinguish between the fractions of vegetation or bare ground covered by snow. The amount of snowmelt is calculated by assuming all of the solar heating will be used when surface temperature is greater than 273.15 K. On the other hand, the newly coupled SLM [22] can have multilayer snow and soil to emulate the physical processes inside snow and soil, including frozen soil, and the effects of soil type on soil heat flux and heat content, soil moisture flux, and evapotranspiration by vegetation. Table 1 summarizes some of the major differences between PRCMLSS and the snow land-surface model (SLM). As with other aspects of surface physics, the use of an interactive snow-soil model marks a vast improvement from the cruder methods used earlier. However, in this experiment the maximum number of soil layers is limited to three layers due to model initial condition constraints. More detailed discussions of SLM processes can be found in Min [30] and Sun and Chern [22].

The existing LSS developed by Bosilovich and Sun [27] does not consider detailed snow hydrology and frozen soil dynamics which are important processes from winter to spring. The control (CTL) run was performed using PRCM-LSS setup with initial and boundary conditions from the European Center for Medium-Range Weather Forecast (ECMWF). The experiment run (EXP1) differs only by the coupling of SLM. The lateral boundary conditions such as temperature, height, and wind fields remain the same as the control run conditions. Other configurations, including model dynamics and physics, except for the land-surface scheme, are identical. The model domain has a horizontal resolution of $45 \mathrm{~km} \times 45 \mathrm{~km}$ over the continental US with 28 vertical sigma layers. A detailed analysis is performed in box 2 over the Northern Plains where the heaviest flooding occurred due to rapid snowmelt (Figure 1). The period chosen for numerical simulations is March and April of 1997. The model runs are initialized a week before the month of 


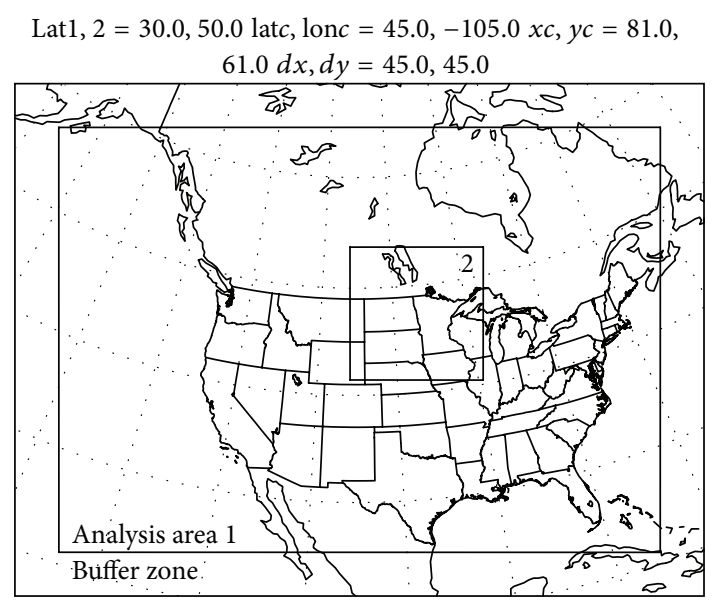

FIgURE 1: Model domain area with buffer zone and analysis areas 1 and 2 used for this study.

March and April and are integrated continuously without nudging or restart. A monthly simulation was performed to avoid potential growth of errors and spin-up issues as recommended by Hong and Kanamitsu [12].

Numerical experiments are designed to test and validate the hypothesis that the presence of snow and its melt from winter to spring affects the propagation of synoptic waves, amounts of precipitation, and floods over the Northern Plains. The new land model has the option to turn on or off the multilayer snow process. But we only present the numerical experiment with detailed snow process turned on in the landsurface model (EXP1).

\section{Results}

In order to study the effects of cold land processes on the simulation of spring snowmelt flooding with a coupled modeling system, we investigate the monthly mean features and the time evolution of the event. We then compare the two model results with the ECMWF data and analyze the hydrologic budgets. Soil moisture initialization in PRCMSLM requires a soil ice amount which is not readily available in conventional surface observations. Thus, we have initially distinguished the amounts of soil ice and liquid based on the soil temperature of $273.15 \mathrm{~K}$, whereas the PRCM-LSS has no soil ice included.

3.1. Horizontal Mean Fields. The PRCM coupled with a multilayer SLM (EXP1) has successfully reproduced the spring snowmelt floods over the Northern Plains of the US during March and April of 1997. Compared with the simple snowsoil parameterization, which consists of one-layer snow and the soil without frozen mechanism (CTL), the simulations from the PRCM with new SLM agree much better with the observations in snow coverage, the surface temperature, pressure, precipitation, and snow accumulation over the flooding area in the Northern Plains of the US (Figures 2 to $5)$.
Figure 2 shows the simulated snow depth (in snow water equivalent $[\mathrm{m}]$ ) and $200 \mathrm{hPa}$ wind vectors averaged for March 1997 versus observations, respectively. NOAA NESDIS (National Environmental Satellite, Data, and Information Service) northern hemisphere SSM/I (Special Sensor Microwave/Imager) snow cover/sea-ice remote sensing data are used for snow comparison (Figure 2(a)). CTL run shows that model simulation of snow depth is underestimated over the Northern Plains while EXP1 shows better agreement in the coverage area (Figure 2(c)). The $200 \mathrm{hPa}$ wind vectors are generally in good agreement with ECMWF reanalysis, which is used as a proxy for observations (Figure 2(d)). The location of the polar jet and its maximum core over the northeast are well represented. The March EXP1 wind field shows a stronger polar jet located over the US and Canadian border with weaker subtropical jet merging into the core over the northeast when compared with CTL. Overall the March 1997 simulation of PRCM-SLM is in better agreement for both magnitude and spatial pattern with the observations.

The albedo calculation in Figure 3 shows the most pronounced differences among all variables. Both monthly mean and its difference with CTL show up to $40 \%$ difference in albedo for March, which significantly reduce the solar radiation absorbed at the ground. The simulation results indicate that coupling of SLM to PRCM is very effective in simulating the cold season regional climate. Figures 4 and 5 show 6 hourly time series of sea-level pressure (SLP) and surface temperature. Both CTL and EXP1 simulate the time variation of surface pressure very well with the passage of synoptic waves (Figure 4). The root mean square error (RMSE) of CTL and EXP1 versus observations for sea-level pressure (SLP) is 1.96 and $1.57 \mathrm{hPa}$, with correlation of 0.92 and 0.95, respectively. On the other hand, EXP1 does much better job in simulating the observed diurnal cycle and synoptic variation of surface temperature (Figure 5). The root mean square error (RMSE) for surface temperature is 2.24 and $1.48 \mathrm{~K}$, with correlation of 0.92 and 0.97 , respectively, for CTL and EXP1.

The effect of including the multilayers of frozen soil and snow lowers the surface temperature due to initial frozen soil and higher albedo over the snow surface, which changes the horizontal temperature gradients and in turn changes the location of synoptic weather systems passing over the cold land region. It affects not only the lower atmosphere but also the upper atmosphere and the large-scale weather systems in mid-to-high latitudes. Remarkable improvement is also found on the geopotential and wind fields at $200 \mathrm{hPa}$ level from the new SLM compared with the previous PRCMLSS simulations. This indicates that, for accurate regional climate model (RCM) simulations with reduced uncertainties, detailed snow-soil parameterization is important to better assess the limits of climate change impacts.

3.2. Vertical Profile. Figure 6 shows the monthly averaged vertical profile of temperature and mixing ratio of CTL (open circle) and EXP1 (green line) and the geopotential height difference for March and April over the entire model domain (box 1 in Figure 1). In general, a significant impact of cold land processes appears in the mid-to-lower atmosphere for 


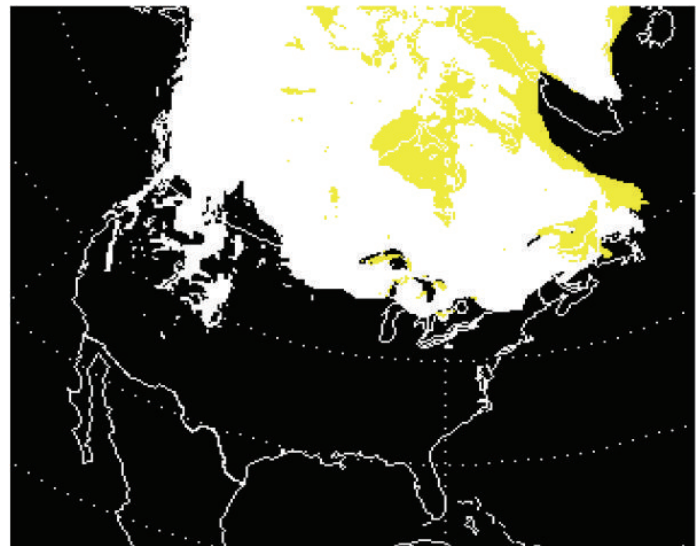

(a)

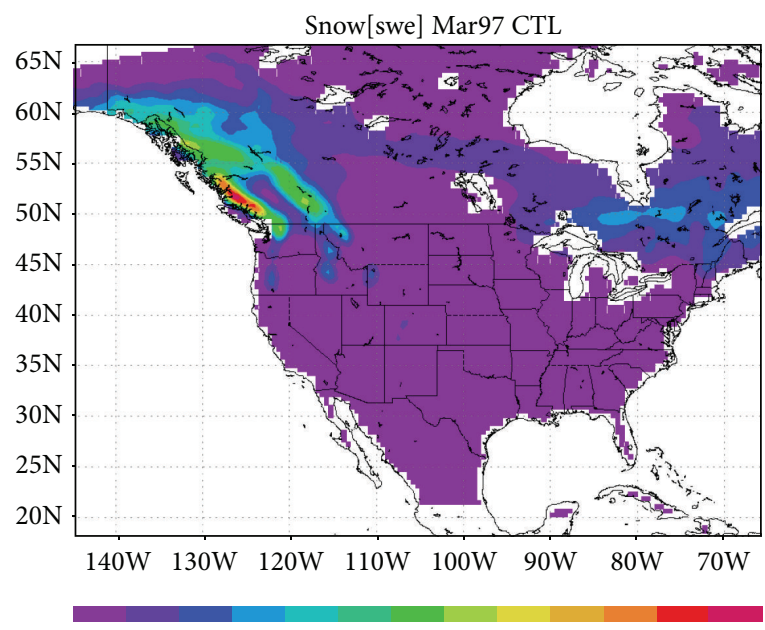

$\begin{array}{llllllllllll}0.2 & 0.4 & 0.6 & 0.8 & 1 & 1.2 & 1.6 & 1.8 & 2 & 2.2 & 2.4 & 2.6\end{array}$

(b)

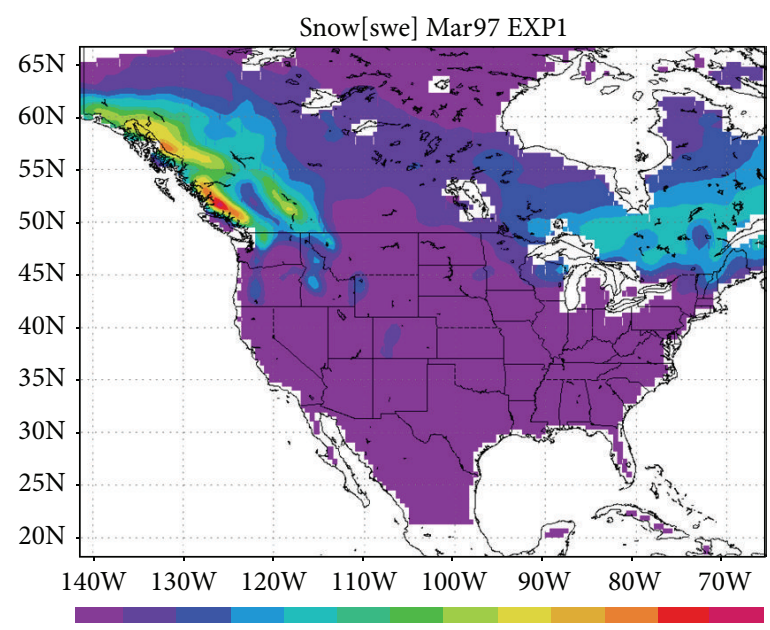

$\begin{array}{llllllllllll}0.05 & 0.1 & 0.15 & 0.2 & 0.3 & 0.35 & 0.4 & 0.45 & 0.55 & 0.6 & 0.65 & 0.7\end{array}$

(c)

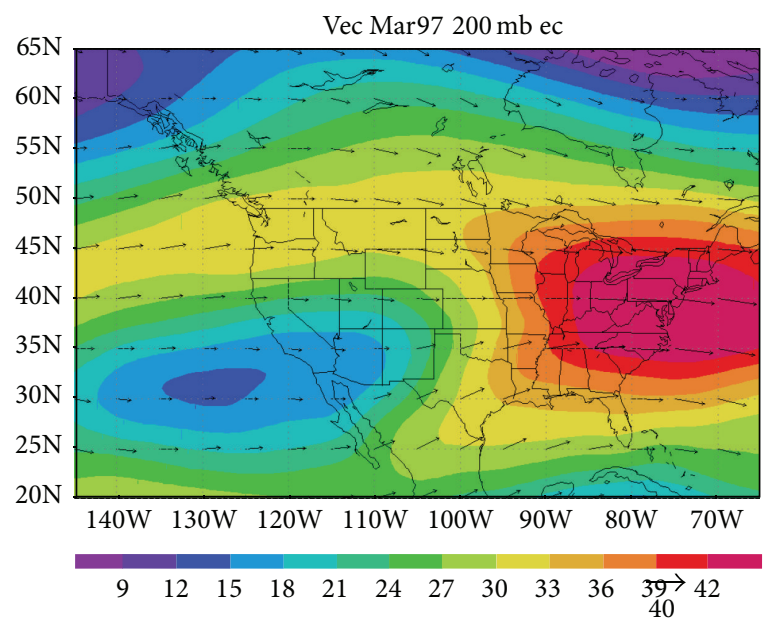

(d)

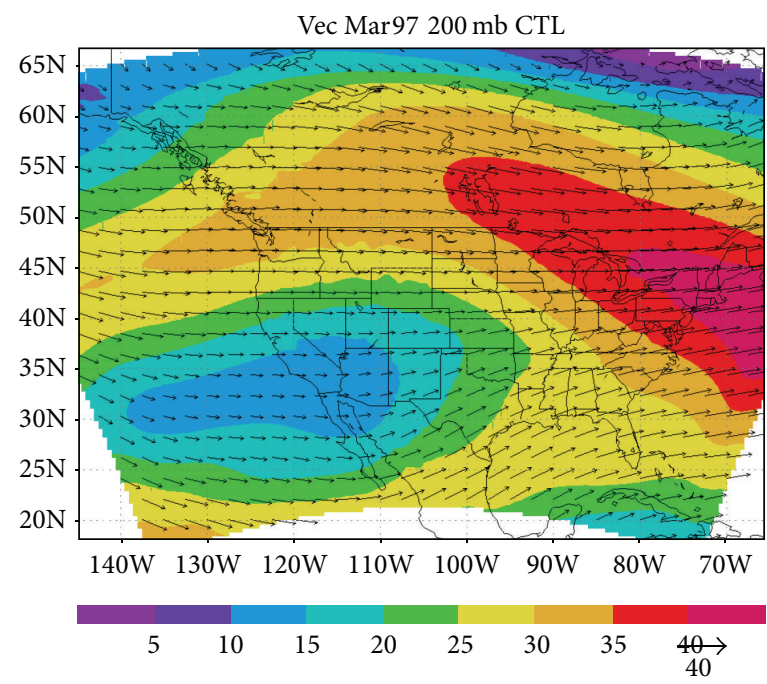

(e)

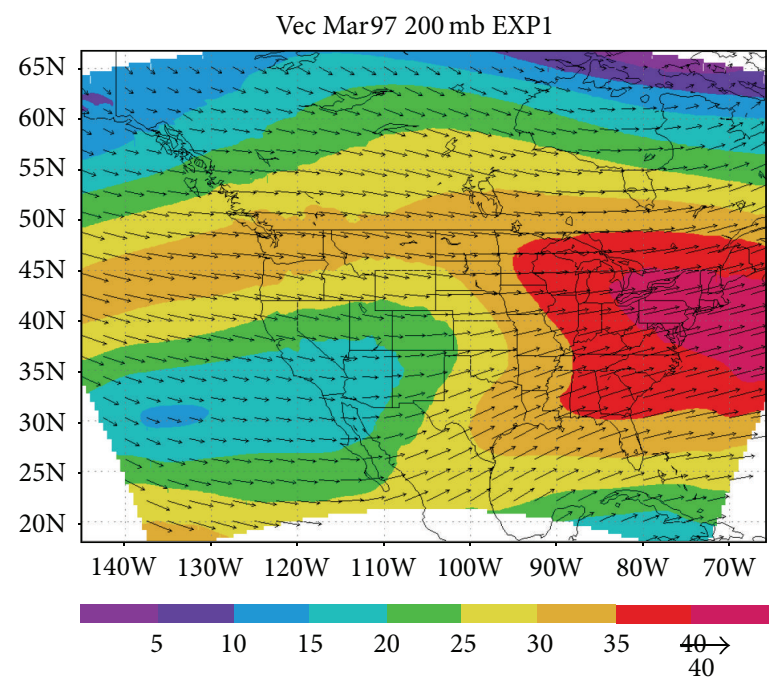

(f)

FIGURE 2: Left: observed (a) and simulated snow depth from CTL (b) and EXP1 (c). Right: monthly mean of $200 \mathrm{hPa}$ wind vector for March 1997 from ECMWF (d), CTL (e), and EXP1 (f), respectively. 


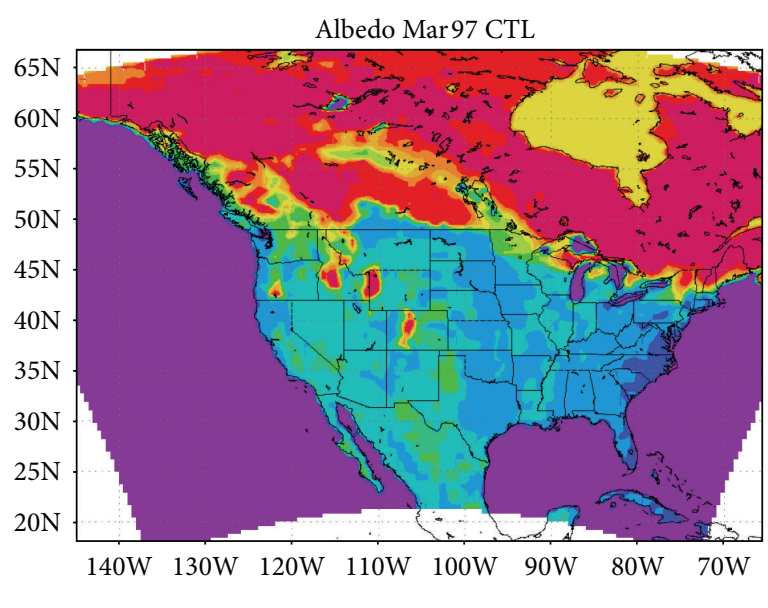

$\begin{array}{llllllllllll}0.15 & 0.2 & 0.25 & 0.3 & 0.35 & 0.4 & 0.5 & 0.55 & 0.6 & 0.65 & 0.7 & 0.75\end{array}$

(a)

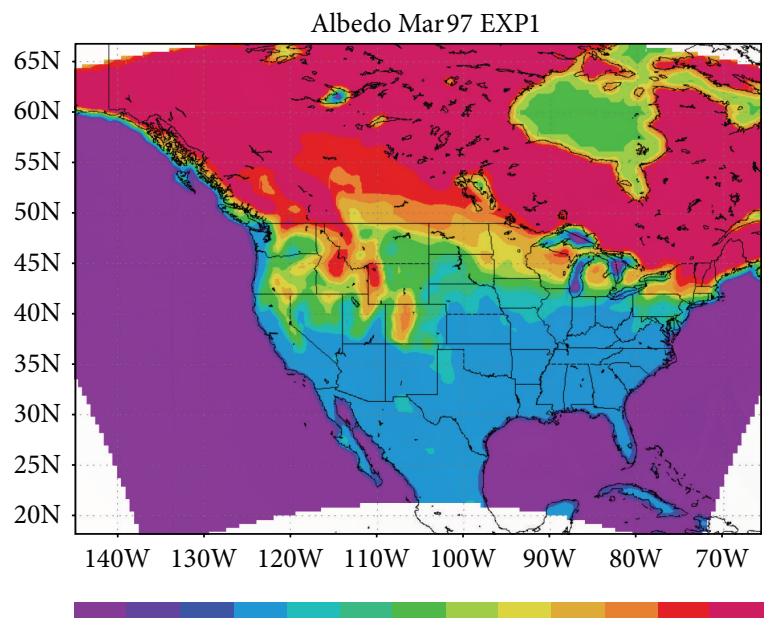

$\begin{array}{llllllllllll}0.15 & 0.2 & 0.25 & 0.35 & 0.4 & 0.45 & 0.55 & 0.6 & 0.65 & 0.75 & 0.8 & 0.85\end{array}$

(b)

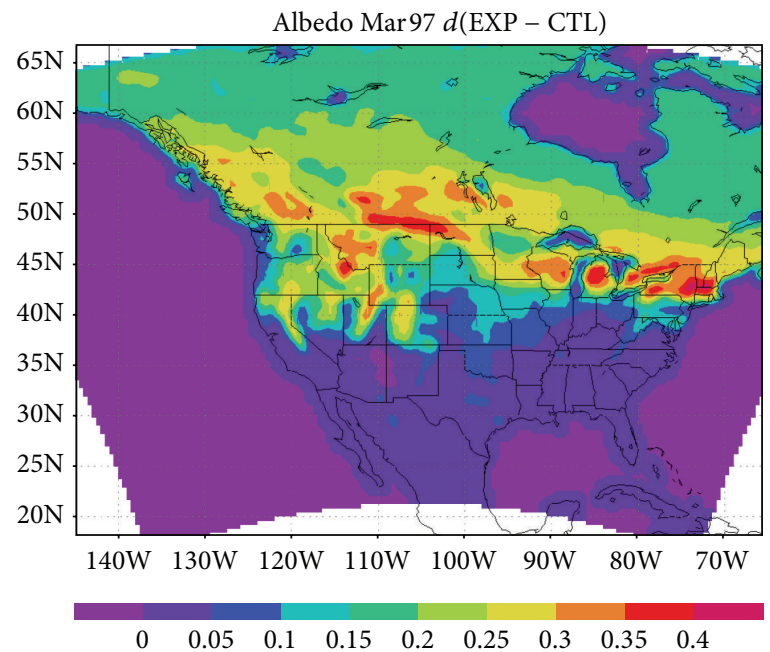

(c)

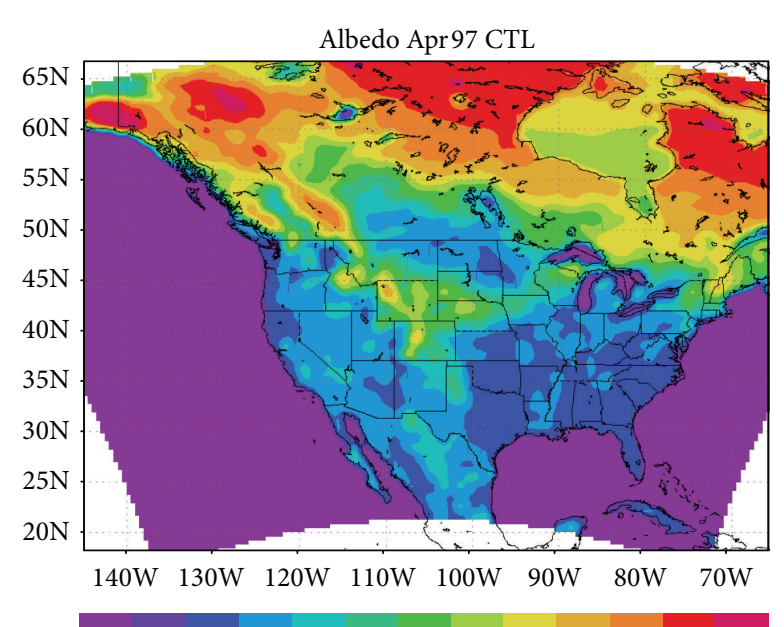

$\begin{array}{llllllllllll}0.15 & 0.2 & 0.25 & 0.3 & 0.35 & 0.4 & 0.45 & 0.5 & 0.55 & 0.6 & 0.65 & 0.7\end{array}$

(d)

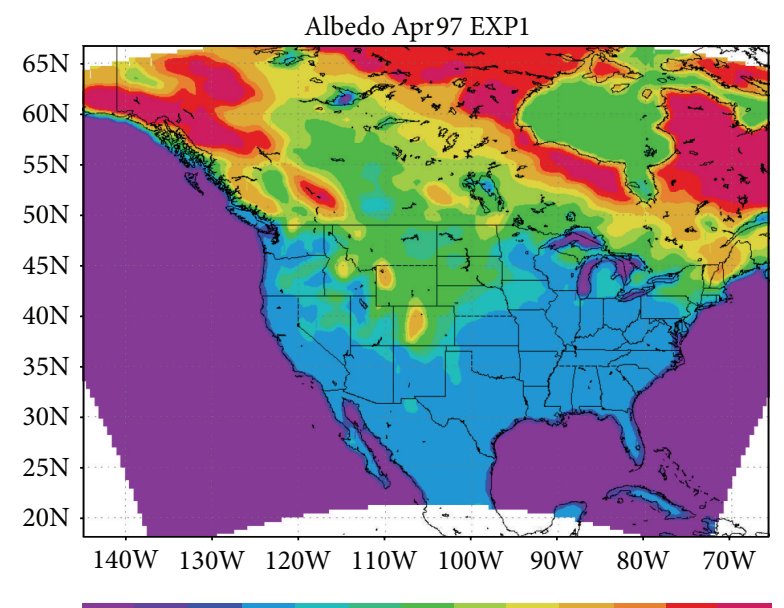

$\begin{array}{llllllllllll}0.15 & 0.2 & 0.25 & 0.35 & 0.4 & 0.45 & 0.55 & 0.6 & 0.65 & 0.75 & 0.8 & 0.85\end{array}$

(e)

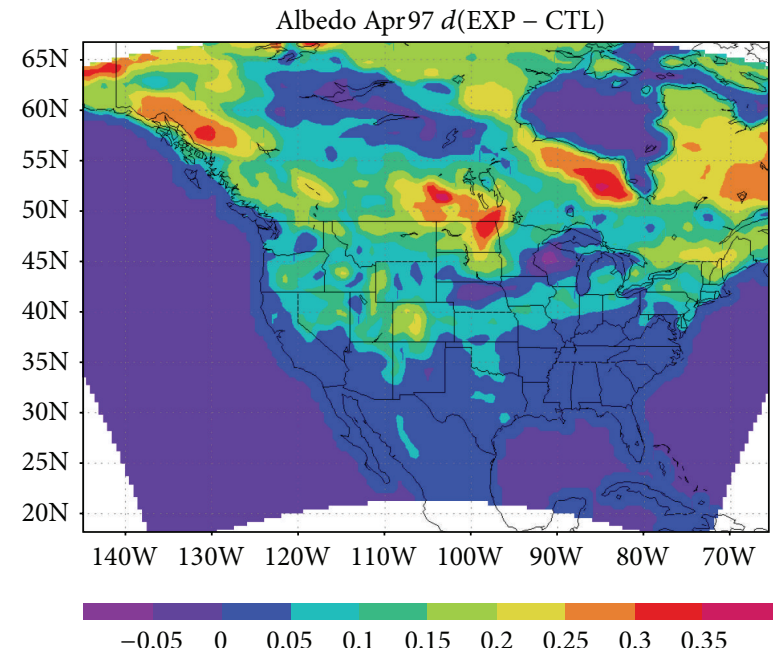

(f)

Figure 3: Simulated mean albedo ((a), (b), (d), and (e)) and the differences ((c), (f)) for March (left panel) and April (right panel) of 1997 from CTL and EXP1, respectively. 


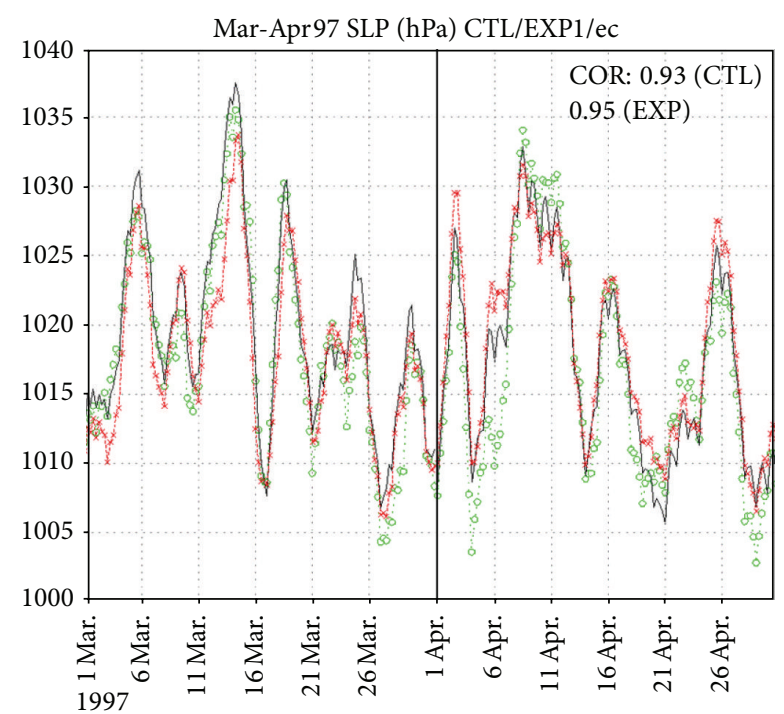

FIgURE 4: Time series of mean sea-level pressure [hPa] for ECMWF (green circle), CTL (red cross), and EXP1 (solid line) simulations in box 2 of Figure 1.

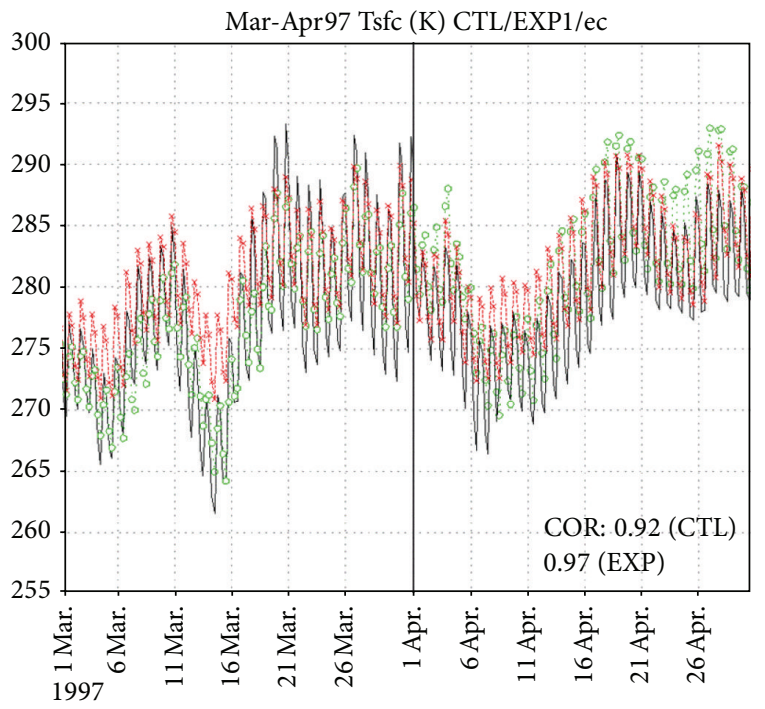

FIgURE 5: Same as Figure 4 except for surface air temperature [K].

both temperature and moisture. Higher surface albedo and initial frozen soil in EXP1 cool and dry the lower atmosphere over the whole domain (Figure 6(a)). Geopotential height difference also shows a significant reduction of the height field for EXP1 (Figure 6(b)). In the atmosphere, the variation of geopotential depends on the temperature, and geopotential height decreases more rapidly in a cold layer than in a warm layer. Therefore, there is a gradual decrease in EXP1 height field up to $200 \mathrm{hPa}$ because the air column below is colder when compared to CTL.

With the additional moisture of CTL in the lower atmosphere and increased precipitation in the central United States, excessive latent heat release heats the mid-to-upper level atmosphere. This decreases the column averaged meridional temperature gradient of CTL; and the speed of upperlevel jet stream is reduced and has more curvature than ECMWF data for March (figures not shown). Intensification of the subtropical jet in April EXP1 can be understood in a similar way. Although the northward retreat and weakening of the polar jet stream is well simulated in both CTL and EXP1, the inclusion of cold season processes (EXP1) results in a stronger column averaged temperature gradient near 30 $40^{\circ} \mathrm{N}$ latitude and colder mid-to-upper level temperatures further up to $250 \mathrm{hPa}$ than CTL. Overall, the effect of cold season processes intensifies both the Canadian high pressure system and the low pressure systems over the Pacific Northwest and the south.

The strengthening of the pressure gradient force between the two systems increases the surface wind, which stimulates low-level mixing of temperature and moisture. The cooling and drying of the lower atmosphere further enhance the reduction of the height field in the mid-to-upper level by hydrostatic balance and increase the meridional temperature gradient. These subsequent processes strengthen the upperlevel wind, thus changing the governing dynamics and atmospheric circulation over the Northern Plains and the North America.

In addition, the strengthening of cold Canadian high pressure system increases the snowfall amount over the Northern Plains when compared with CTL in March and in early April. Increased snowfall also increases the surface albedo, which further cools the surface temperature by reducing the solar radiation reaching ground. We consider this feature as a direct effect of the cold season processes. On the other hand, increase in precipitation over the major storm pathways can be considered as an indirect effect of cold season processes since the shift in synoptic weather patterns locates the storm systems in a more favorable position with respect to upper-level dynamics.

3.3. Water Budget. Since the interaction among snow, precipitation, and soil in a three-dimensional model is a highly complicated, nonlinear process, it is difficult to identify the exact role of cold season processes in affecting the subsequent precipitation simulation. In this subsection, we further investigate the role of snow-soil-precipitation interaction by analyzing atmospheric water budget.

The amount of moisture in the atmosphere is one of the most important factors in determining the severity of storm systems since excessive precipitation can cause wide area of flooding disaster. Analyzing the moisture budget is a common and useful method for diagnosing flood-producing storms and precipitation. The moisture budget equation of an atmospheric column in sigma coordinate can be written as

$$
\frac{1}{g} \int_{0}^{1} \frac{\partial p^{*} q}{\partial t} d \sigma=-\frac{1}{g} \int_{0}^{1} \nabla \cdot\left(p^{*} q \vec{V}\right) d \sigma+E-P+D,
$$

where $q$ is specific humidity, $p^{*}$ is the total pressure of the column, $\vec{V}$ is the three-dimensional wind vector, $E$ is surface evaporation, $P$ is precipitation reaching the ground, and $D$ is diffusion and subgrid flux of water vapor. The 


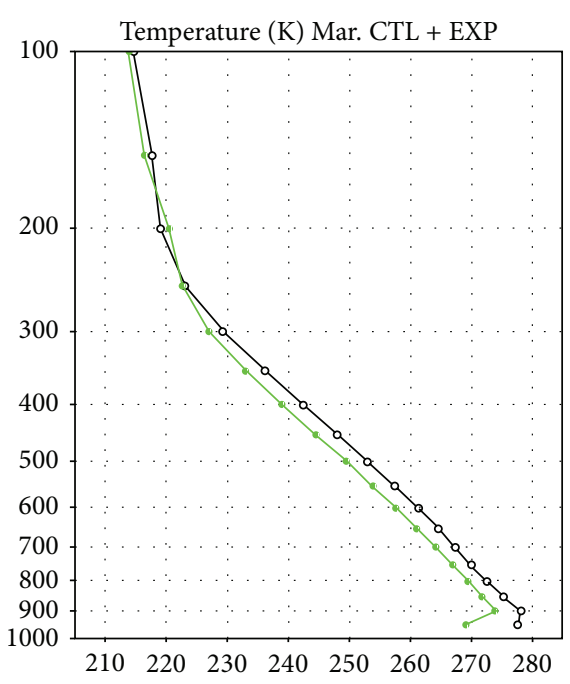

(a)

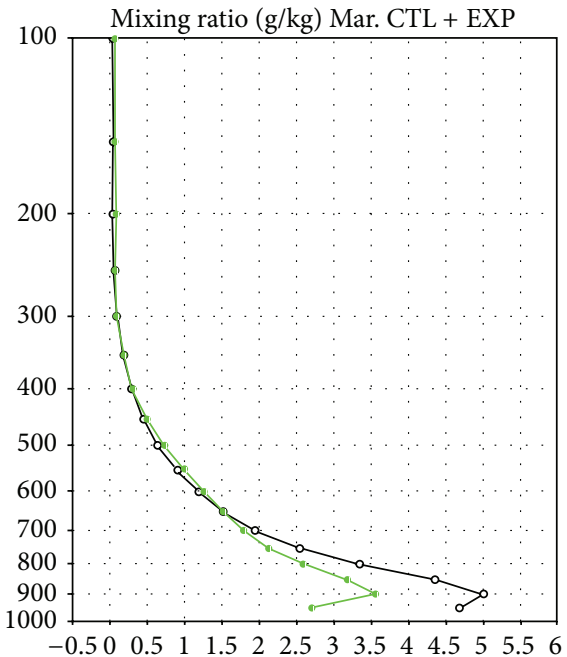

(b)

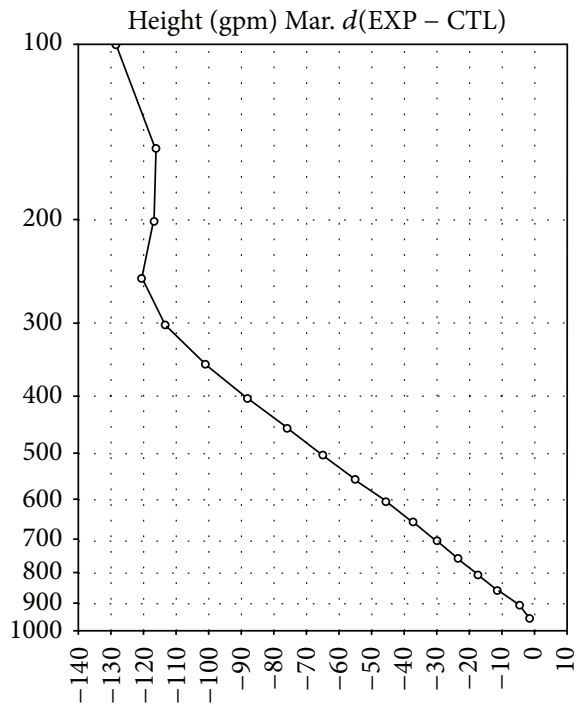

(c)

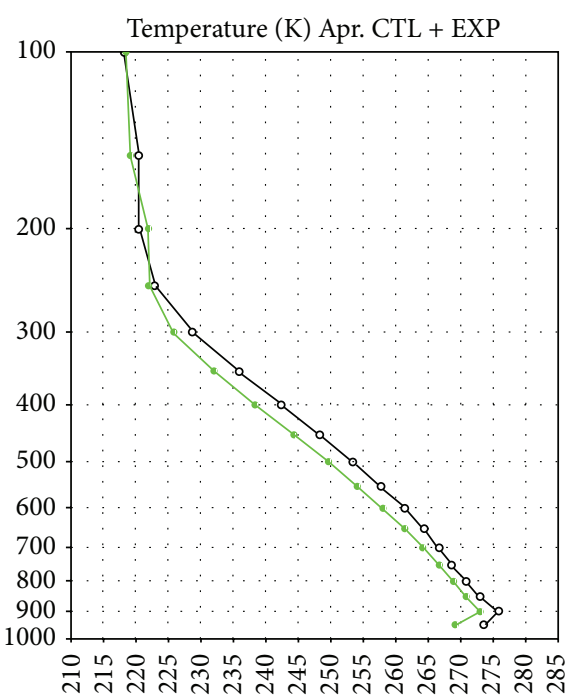

(d)

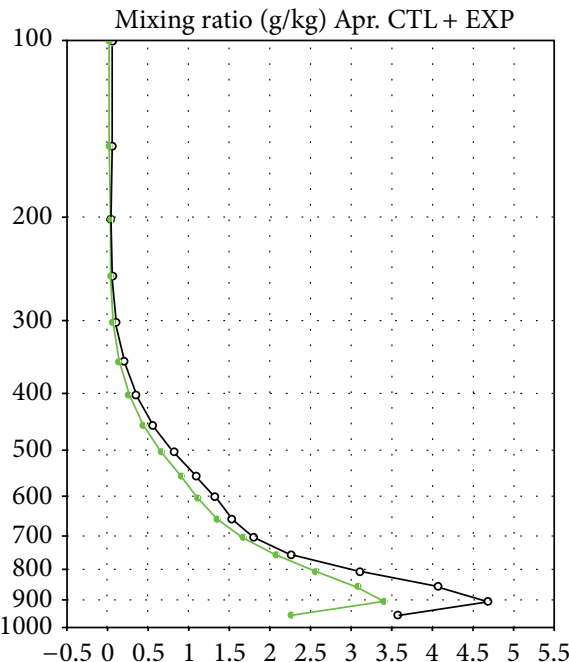

(e)

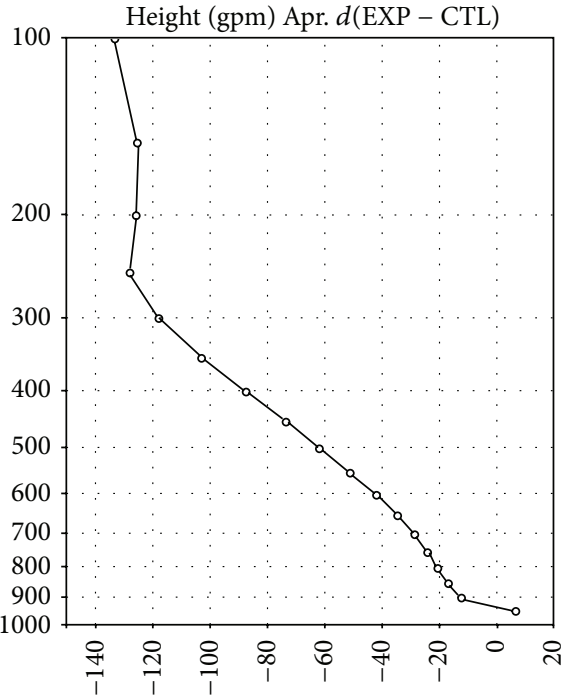

(f)

FIGURE 6: Vertical profile of temperature ((a), (d)) and mixing ratio ((b), (e)) of CTL (open circle) and EXP1 (green line) and the geopotential height differences ((c), (f)) for March (left panel) and April (right panel) over the entire model domain. 


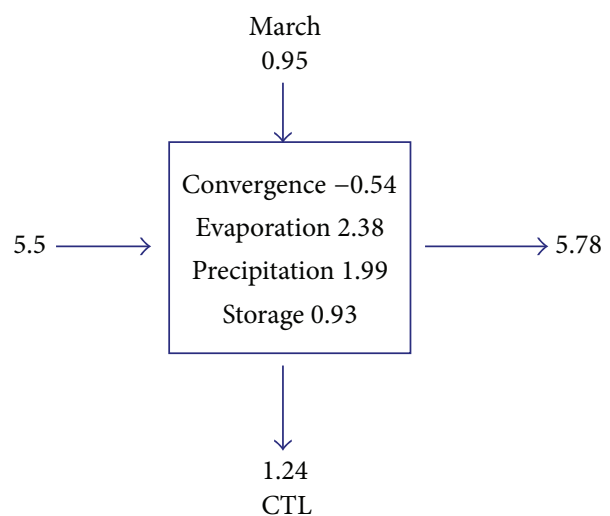

(a)

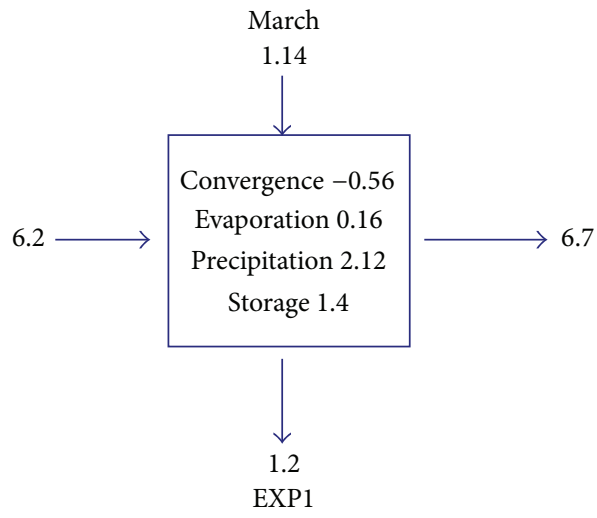

(b)

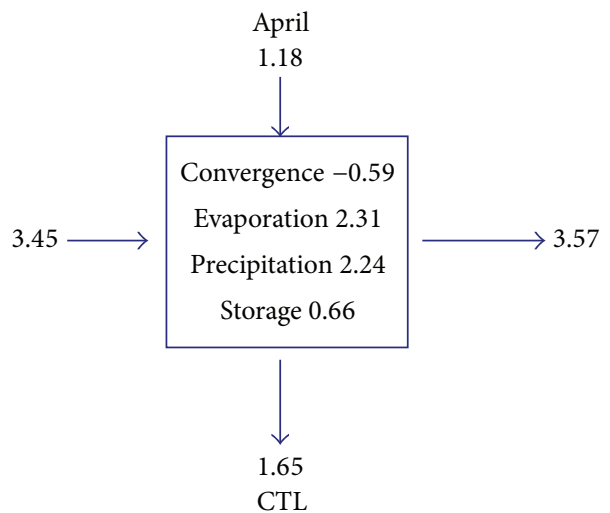

(c)

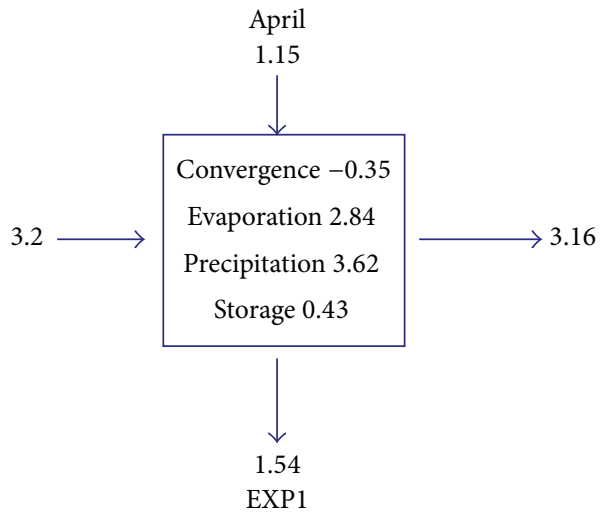

(d)

Figure 7: Atmospheric moisture budgets for box 2 shown in Figure 1 for March ((a)-(b)) and April ((c)-(d)) of CTL and EXP1, respectively. Units are in $\left[\mathrm{mm} \mathrm{day}^{-1}\right]$.

moisture that contributes to precipitation $(P)$ could come from the moisture storage in the column (left-hand side of the equation), surface evaporation $(E)$, moisture convergence (first term on the right-hand side of the equation), and/or moisture diffusion through the boundary $(D)$. We use numerical results to calculate each term of (1) except $D$, which is calculated as a residual of the equation.

Figure 7 shows March and April box area-averaged moisture budgets for the Northern Plains (see Figure 1). In March, CTL shows much more evaporation than precipitation due to warmer temperatures and early snowmelt; thus, $P-E<$ 0 (Figure $7(\mathrm{a})$ ). In contrast, EXP1 shows only a fraction of evaporation occurring over the boxed area due to colder land surface but the total precipitation amount is similar to CTL; thus, $P-E>0$ (Figure 7(b)). An interesting fact to be noted is that both cases show a net moisture divergence out of the region. In April, the conditions differ more between CTL and EXP1 than in March. The total amount of moisture transport within the region is similar to March (Figure 7(c)). However, EXP1 shows slightly more precipitation and evaporation compared to CTL (Figure $7(\mathrm{~d})$ ). This can be attributed to the fact that colder surface temperatures prohibited early snowmelt. As a result, warmer surface temperatures in late
April and added precipitation drastically increased moisture availability at the surface, thus producing snowmelt flooding over Minnesota and the Dakotas. This is in good agreement with the actual event that occurred during the spring of 1997.

3.4. Statistics. The mean bias and correlation between model simulation of CTL and EXP1 compared with ECMWF reanalysis data for March and April 1997 are shown in Table 2. The upper-level statistical comparison of geopotential height $(\mathrm{GH})$, temperature $(T)$, wind, and specific humidity $(Q)$ at $850,700,500$, and $200 \mathrm{hPa}$ shows much improvement in cold season simulation with the new SLM since the deviation from the proxy observations is small. However, the temperatures at 700 and $500 \mathrm{hPa}$ midlevel show slight cold bias of $0.5 \sim 1 \mathrm{~K}$, but the bias of moisture and geopotential fields is significantly reduced.

\section{Discussion and Conclusion}

The coupling of multilayer SLM to the PRCM shows a drastic climate change when simulating the spring snowmelt floods over the Northern Plains during March and April, 
TABLE 2: March (M) and April (A) mean statistics of CTL and EXP1 compared with ECMWF reanalysis.

\begin{tabular}{|c|c|c|c|c|c|c|c|c|}
\hline \multirow{3}{*}{ Level } & \multicolumn{4}{|c|}{ CTL } & \multicolumn{4}{|c|}{ EXP1 } \\
\hline & \multicolumn{2}{|c|}{ Bias } & \multicolumn{2}{|c|}{$\mathrm{COR}$} & \multicolumn{2}{|c|}{ Bias } & \multicolumn{2}{|c|}{ COR } \\
\hline & $\mathrm{M}$ & $\mathrm{A}$ & M & A & $\mathrm{M}$ & A & $\mathrm{M}$ & A \\
\hline \multicolumn{9}{|l|}{$850 \mathrm{hPa}$} \\
\hline $\mathrm{GH}[\mathrm{m}]$ & 4.8 & 1.72 & 0.93 & 0.96 & 1.63 & 0.37 & 0.97 & 0.98 \\
\hline$Q\left[\mathrm{gkg}^{-1}\right]$ & $3.09 E-01$ & $2.50 E-01$ & 0.81 & 0.82 & $9.74 E-03$ & $1.23 E-01$ & 0.87 & 0.85 \\
\hline \multicolumn{9}{|l|}{$700 \mathrm{hPa}$} \\
\hline$T[\mathrm{~K}]$ & 0.98 & -0.26 & 0.97 & 0.94 & -1.24 & -1.22 & 0.96 & 0.92 \\
\hline$Q\left[\mathrm{gkg}^{-1}\right]$ & $2.56 E-01$ & $2.44 E-01$ & 0.82 & 0.83 & $1.74 E-01$ & $5.57 E-02$ & 0.86 & 0.88 \\
\hline \multicolumn{9}{|l|}{$500 \mathrm{hPa}$} \\
\hline $\mathrm{GH}[\mathrm{m}]$ & 19.15 & 10.99 & 0.91 & 0.93 & -4.79 & -7.47 & 0.97 & 0.95 \\
\hline$T[\mathrm{~K}]$ & 1.16 & 0.786 & 0.94 & 0.96 & -0.36 & -0.559 & 0.98 & 0.97 \\
\hline \multicolumn{9}{|l|}{$200 \mathrm{hPa}$} \\
\hline$T[\mathrm{~K}]$ & -0.241 & -0.514 & 0.96 & 0.94 & 0.73 & 0.122 & 0.91 & 0.97 \\
\hline Wind $\left[\mathrm{ms}^{-1}\right]$ & 0.53 & -0.739 & 0.90 & 0.85 & 0.78 & -0.33 & 0.97 & 0.98 \\
\hline
\end{tabular}

1997. In order to extend the model's capability to simulate the accumulation and melting of snow on the ground and freezing and thawing inside the soil, a land-surface model needs to include detailed physics and thermodynamics of cold season processes. With more accurate descriptions of atmosphere-land interactions and the use of high-resolution land-surface initial conditions, there is potential to better predict snowmelt flooding, river routing, and decrease its damage to agriculture, property, and human life.

Compared with the PRCM-LSS simulation, the PRCMSLM shows marked differences in surface and ground temperature, precipitation, and albedo calculations. In general, the intensity and location of precipitation over the Northern Plains region were in better agreement with PRCM-SLM. Overall, the regional climate simulation of March and April 1997 with the inclusion of the detailed frozen soil and snow processes improves the synoptic and local circulations during the cold season as well as the diurnal cycle of surface temperature and pressure. The effect of including cryosphere model physics lowers the surface temperatures due to, in part, the initial frozen soil conditions and to the reduction of incoming solar radiation at the surface due to higher albedo over the snow covered region-opposite to snow-albedo feedback mechanism, which implies warming. These affect the horizontal temperature gradients and in turn change the location of synoptic weather systems and the baroclinic zone. In addition, the partitioning of incoming radiative energy is sensitive to snowmelt and soil freeze/thaw conditions during the early stages of the model simulations.

The limitation of this study is that the experiments are only conducted for the melting season. To test the robustness of RCMs with SLM and to better understand the changes in regional climates, further continuation of this work with more sensitivity study is needed.

When observational data are limited, numerical models become a major tool in studying the physics and interactions of land-surface phenomena. This is especially true during the cold season and at high latitudes. In this coupled modeling study, we identified the important factors and processes that influence late winter to early spring regional scale water and energy cycles at different spatial and time scales. The implications from our results indicate that RCMs need to have detailed multilayer snow and frozen soil processes to create realistic cold season simulations and prevent climate drift in climate studies. This study also shows promise that quantitative forecasting of precipitation and flooding caused by winter-to-spring snowmelt can be improved with coldland physics and thermodynamics in future warming climate change studies.

\section{Conflict of Interests}

The authors declare that there is no conflict of interests regarding the publication of this paper.

\section{Acknowledgments}

This study was partially supported by Kyungpook National University Research Fund, 2014, and by the Center for Atmospheric REmote Sensing (CARE). The authors appreciate the constructive comments of the reviewer and the editor.

\section{References}

[1] D. S. Gutzler and J. W. Preston, "Evidence for a relationship between spring snow cover in North America and summer rainfall in New Mexico," Geophysical Research Letters, vol. 24, no. 17, pp. 2207-2210, 1997.

[2] E. E. Small, "The influence of soil moisture anomalies on variability of the North American monsoon system," Geophysical Research Letters, vol. 28, no. 1, pp. 139-142, 2001.

[3] M. G. Bosilovich and W.-Y. Sun, "Numerical simulation of the 1993 midwestern flood: Local and remote sources of water," Journal of Geophysical Research D: Atmospheres, vol. 104, no. 16, pp. 19415-19423, 1999.

[4] M. Zhang, K.-H. Min, Q. Wu, J. Zhang, and J. Harbor, "A new method to determine the upper boundary condition of a permafrost thermal model: an example from the Qinghai-Tibet 
Plateau," Permafrost and Periglacial Processes, vol. 23, no. 4, pp. 301-311, 2012.

[5] R. D. Koster and M. J. Suarez, "Relative contributions of land and ocean processes to precipitation variability," Journal of Geophysical Research, vol. 100, no. 7, pp. 1375-1390, 1995.

[6] P. R. Houser, "Land data assimilation systems," NASA Tech. Memo, 2000.

[7] M. Stieglitz, A. Ducharne, R. Koster, and M. Suarez, "The impact of detailed snow physics on the simulation of snow cover and subsurface thermodynamics at continental scales," Journal of Hydrometeorology, vol. 2, no. 3, pp. 228-242, 2001.

[8] E.-S. Im, J.-B. Ahn, and D.-W. Kim, "An assessment of future dryness over Korea based on the ECHAM5-RegCM3 model chain under A1B emission scenario," Asia-Pacific Journal of Atmospheric Sciences, vol. 48, no. 4, pp. 325-337, 2012.

[9] A. Di Luca, R. de Elía, and R. Laprise, "Potential for small scale added value of RCM's downscaled climate change signal," Climate Dynamics, vol. 40, no. 3-4, pp. 601-618, 2013.

[10] J.-W. Lee, S.-Y. Hong, E.-C. Chang, M.-S. Suh, and H.-S. Kang, "Assessment of future climate change over East Asia due to the RCP scenarios downscaled by GRIMs-RMP," Climate Dynamics, vol. 42, no. 3-4, pp. 733-747, 2014.

[11] W.-Y. Sun, K.-H. Min, and J.-D. Chern, "Numerical study of 1998 late summer flood in East Asia," Asia-Pacific Journal of Atmospheric Sciences, vol. 47, no. 2, pp. 123-135, 2011.

[12] S.-Y. Hong and M. Kanamitsu, "Dynamical downscaling: fundamental issues from an NWP point of view and recommendations," Asia-Pacific Journal of Atmospheric Sciences, vol. 50, no. 1, pp. 83-104, 2014.

[13] S.-G. Oh, M.-S. Suh, and D.-H. Cha, "Impact of lateral boundary conditions on precipitation and temperature extremes over South Korea in the CORDEX regional climate simulation using RegCM4," Asia-Pacific Journal of Atmospheric Sciences, vol. 49, no. 4, pp. 497-509, 2013.

[14] J.-W. Lee and S.-Y. Hong, "Potential for added value to downscaled climate extremes over Korea by increased resolution of a regional climate model," Theoretical and Applied Climatology, vol. 117, pp. 667-677, 2014.

[15] K.-H. Seol and S.-Y. Hong, "Relationship between the Tibetan snow in spring and the East Asian summer monsoon in 2003: a global and regional modeling study," Journal of Climate, vol. 22, no. 8, pp. 2095-2110, 2009.

[16] E. A. Anderson, "A point energy and mass balance model of a snow cover," NOAA Technical Report, vol. 19, p. 150, 1976.

[17] D. L. Verseghy, "CLASS-a Canadian land surface scheme for GCMs. I. Soil model," International Journal of Climatology, vol. 11, no. 2, pp. 111-133, 1991.

[18] M. Stieglitz, D. Rind, J. Famiglietti, and C. Rosenzweig, "An efficient approach to modeling the topographic control of surface hydrology for regional and global climate modeling," Journal of Climate, vol. 10, no. 1, pp. 118-137, 1997.

[19] G. Bonan, "A land surface model for ecological, hydrological, and atmospheric studies," NCAR Technical Note NCAR/TN417+STR, 1996.

[20] Y. Dai, X. Zeng, R. E. Dickinson et al., "The common land model," Bulletin of the American Meteorological Society, vol. 84, no. 8, pp. 1013-1023, 2003.

[21] M. B. Ek, K. E. Mitchell, Y. Lin et al., "Implementation of Noah land surface model advances in the National Centers for Environmental Prediction operational mesoscale Eta model," Journal of Geophysical Research D: Atmospheres, vol. 108, no. D22, 2003.
[22] W.-Y. Sun and J.-D. Chern, "One dimensional snow-land surface model applied to sleepers experiment," Boundary-Layer Meteorology, vol. 116, pp. 95-115, 2005.

[23] J. Jin, X. Gao, Z.-L. Yang et al., "Comparative analyses of physically based snowmelt models for climate simulations," Journal of Climate, vol. 12, no. 8, pp. 2643-2657, 1999.

[24] A. Aaron and P. Etchevers, "An intercomparison of three snow schemes of varying complexity coupled to the same land surface model: local-scale evaluation at an alpine site," Journal of Hydrometeorology, vol. 2, no. 4, pp. 374-394, 2001.

[25] R. Jordon, "A one-dimensional temperature model for a snow cover," Special Report 91-16, U.S. Army Corps of Engineers, Cold Regions Research and Engineering Laboratory, 1991.

[26] J. D. Chern, Numerical simulations of cyclogenesis over the Western United States [Ph.D. thesis], Department of Earth and Atmospheric Sciences, Purdue University, West Lafayette, Ind, USA, 1994.

[27] M. G. Bosilovich and W.-Y. Sun, "Monthly simulation of surface layer fluxes and soil properties during FIFE," Journal of the Atmospheric Sciences, vol. 55, no. 7, pp. 1170-1184, 1998.

[28] W.-Y. Sun, "Pressure gradient in a sigma coordinate," Terrestrial Atmospheric and Oceanic Sciences, vol. 4, pp. 579-590, 1995.

[29] S.-H. Chen and W.-Y. Sun, "A one-dimensional time dependent cloud model," Journal of the Meteorological Society of Japan, vol. 80, no. 1, pp. 99-118, 2002.

[30] K.-H. Min, Coupled cryosphere model development for regional climate study and the initialization of Purdue regional model with the land data assimilation system [Ph.D. thesis], Deptartment of Earth \& Atmospheric Sciences, Purdue University, 2005.

[31] M. G. Bosilovich and W.-Y. Sun, "Formulation and verification of a land surface parameterization for atmospheric models," Boundary-Layer Meteorology, vol. 73, no. 4, pp. 321-341, 1995.

[32] M.-D. Chou and M. J. Suarez, "A solar radiation parameterization for atmospheric studies," NASA Technical Memo, vol. 15, p. 40, 2001.

[33] W. Y. Sun, WR. Hsu, J. D. Chern et al., "Purdue atmospheric models and applications," in Recent Progress in Atmospheric Sciences: Applications to the. Asia-Pacific Region, K. N. Liao and M. D. Chou, Eds., pp. 200-230, World Scientific, Singapore, 2008.

[34] R. A. Pielke Jr., "Who decides? Forecasts and responsibilities in the 1997 Red River flood," Applied Behavioral Science Review, vol. 7, no. 2, pp. 83-101, 1999. 

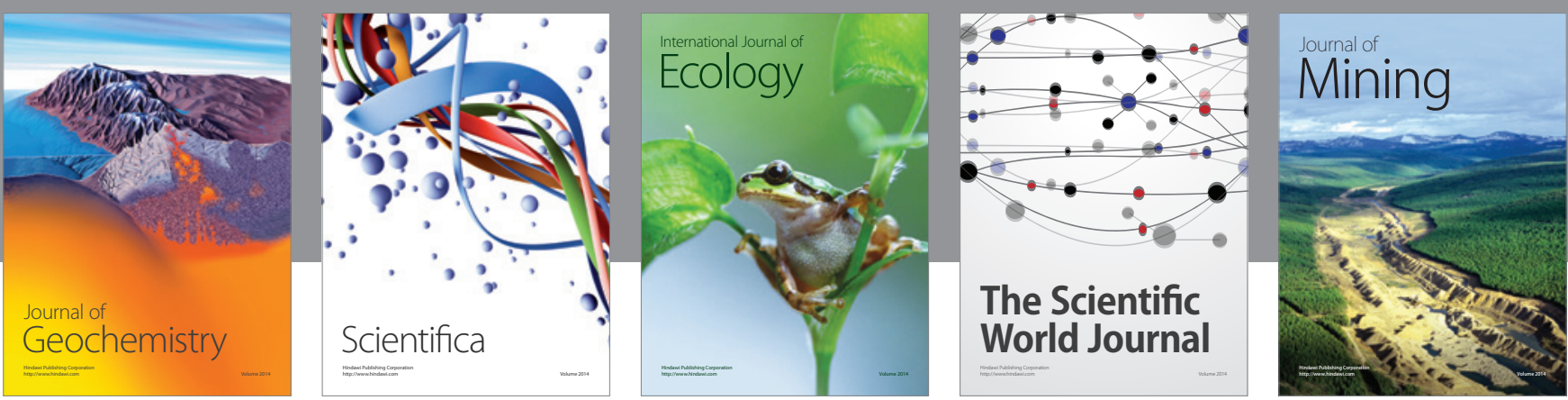

The Scientific World Journal
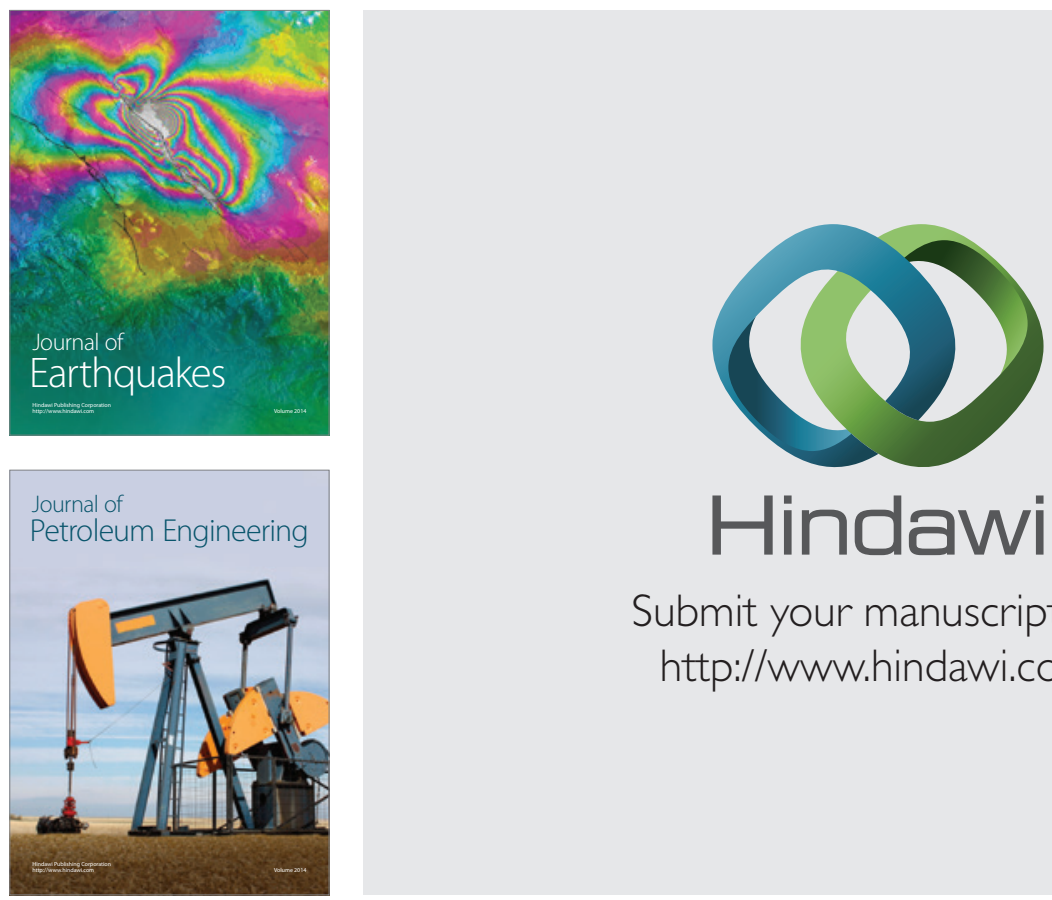

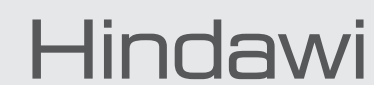

Submit your manuscripts at

http://www.hindawi.com
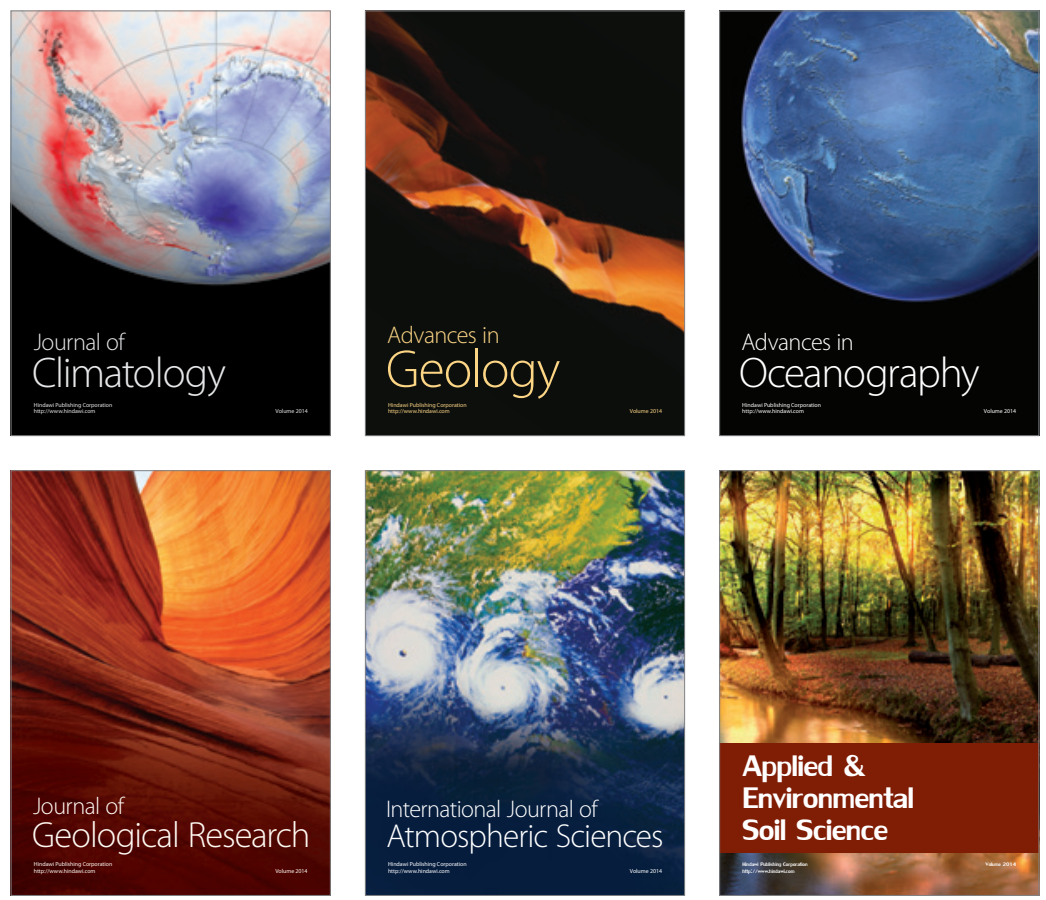
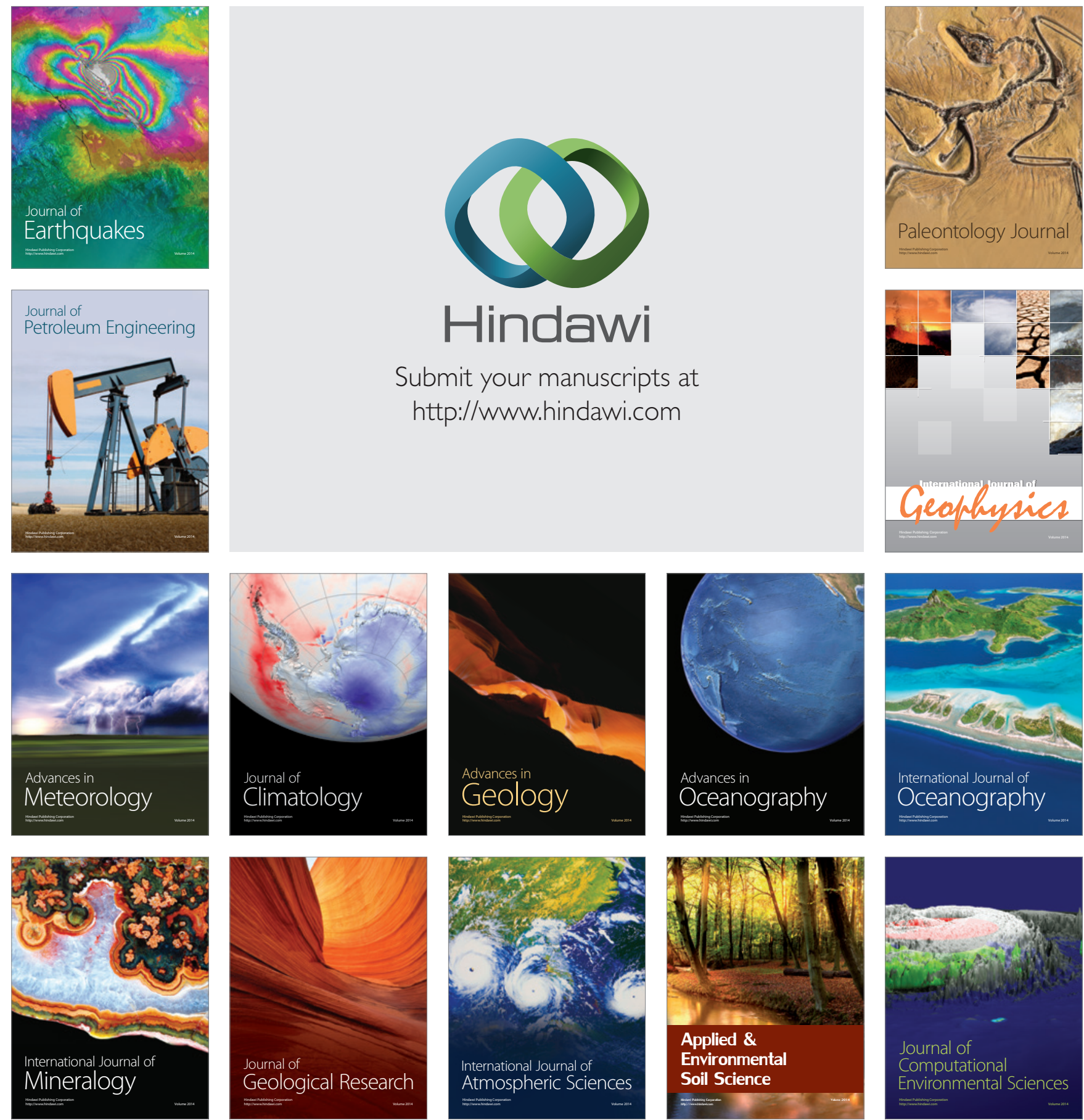